\title{
Ameliorative role of salicylic acid and spermidine in the presence of excess salt in Lycopersicon esculentum
}

\author{
Q. FARIDUDDIN",+, T.A. KHAN*, M. YUSUF*, S.T. AAFAQEE*, and R.R.A.E. KHALIL ${ }^{* *}$ \\ Plant Physiology and Biochemistry Section, Department of Botany, Aligarh Muslim University, Aligarh-202002, India* \\ Department of Botany, Faculty of Science, Benha University, Benha, Egypt ${ }^{* *}$
}

\begin{abstract}
Salicylic acid (SA) and polyamines (PA) are widely used to overcome various abiotic stresses including salt ( $\mathrm{NaCl})$ stress in plants. In the present investigation, co-application efficacies of SA and PA on the salt stress $(200 \mathrm{mM} \mathrm{NaCl})$ were evaluated in Lycopersicon esculentum. After transplantation, at 10-d stage, seedlings were exposed to $\mathrm{NaCl}$ through soil and then allowed to grow till 30-d stage. At 31-d stage of growth, plants were sprayed with double distilled water (control) or spermidine $(1.0 \mathrm{mM})$ and/or SA $\left(10^{-5} \mathrm{M}\right)$. The salt stress significantly reduced the growth, gas-exchange parameters, but increased antioxidant enzymes and proline content in the leaves. Moreover, the loss caused by salt stress was successfully restored by the following treatment of spermidine and SA.
\end{abstract}

Additional key words: abiotic stress; antioxidant; photosynthesis; proline.

\section{Introduction}

Salinity stress is a major limiting factor for sustainable productivity, especially of glycophytic plants, such as cucumber and tomato. Soil salinity is a universal problem that affects nearly $20 \%$ of flooded land and reduces crop yields significantly (Qadir et al. 2014). A high salt content in the soil affects the soil porosity, decreases the soil water potential (Hopkins and Huner 2009), and also affects physiology of plants at the cellular as well as the whole plant level (Murphy and Durako 2003). Plant growth is particularly affected by osmotic stress-specific ion toxicity, ion imbalance, and oxidative stress generated by salt stress (Li et al. 2010). Salt affects various morphological, physiological, and biochemical processes (Koca et al. 2007), such as photosynthesis through changes in gas exchange, pigment content, chloroplast development, and also decline in chlorophyll (Chl) fluorescence and accumulation of low-molecular-mass compounds, such as proline, glycine betaine (Mutlu and Bozcuk 2005, Yusuf et al. 2008, Mir et al. 2015), and proteins (Unni and Rao 2001). An excessive amount of sodium ions in the cells also causes the inhibition of enzymes, such as those for nitrogen metabolism and carbon fixation (Soussi et al.
1998). Ionic imbalance induced by salt stress causes high $\mathrm{Na}^{+}$concentration in plants and it also influences the uptake of other ions, particularly, $\mathrm{K}^{+}$and $\mathrm{Ca}^{2+}$. The accumulation of toxic amounts of salts leads to the hyperosmotic stress in plants that ultimately stimulates the production of reactive oxygen species (ROS) (Ahmad et al. 2009), dehydration, and turgor loss in cells and tissues (Mittler 2002).

Salicylic acid (SA), a ubiquitous plant phenolic acid, is recognized as an endogenous regulator of plant metabolism. It has been found to generate a wide range of metabolic and physiological responses in plants by affecting their growth and development and it improves plant growth (Khodary 2004), transpiration rates, stomatal regulation, photosynthesis (Arfan et al. 2007), and ion uptake and transport (Manaa et al. 2014). The role of SA in defense mechanism under both biotic and abiotic stresses suggests that it also alleviates the salt stress in plants (Tissa et al. 2000, Al-Hakimi and Hamada 2001, Bosch et al. 2007, Jayakannan et al. 2015). Exogenous SA could regulate the activities of antioxidative enzymes and increase plant tolerance to abiotic stresses (He et al. 2002,

Received 5 October 2016, accepted 6 March 2017, published as online-first 12 April 2017.

${ }^{+}$Corresponding author; email: qazi farid@yahoo.com

Abbreviations: $C_{\mathrm{i}}$ - intercellular $\mathrm{CO}_{2}$ concentration; $\mathrm{CA}$ - carbonic anhydrase; $\mathrm{CAT}$ - catalase; Chl - chlorophyll; DAS - days after sowing; DDW - double distilled water; DM - dry mass; FM - fresh mass; $g_{\mathrm{s}}$ - stomatal conductance; LSD - least significant difference; NR - nitrate reductase; PA - polyamines; POX - peroxidase; $P_{\mathrm{N}}$ - net photosynthetic rate; ROS - reactive oxygen species; SA - salicylic acid; Spd - spermidine; SOD - superoxide dismutase; SPAD - soil and plant analysis development.

Acknowledgements: The authors gratefully acknowledge financial support provided by the Council of Science and Technology, Uttar Pradesh [Project No. CST/D-615], India. 
Yusuf et al. 2008, Parashar et al. 2014). It has a regulatory effect on activating biochemical pathways associated with tolerance mechanisms in plants (Najafian et al. 2009). Moreover, SA treatment supported tolerance against copper toxicity in cucumber and tobacco (Strobel and Kuc 1995). In Cassia tora, SA enhanced Al tolerance by increasing the citrate efflux of the roots and thus inhibiting Al uptake (Yang et al. 2003). It was revealed that $\mathrm{Al}$ increased the concentration of SA in the roots. Cd treatment increased the endogenous free SA content in barley (Metwally et al. 2003) and in maize (Pal et al. 2005). Polyamines (PA) are low-molecular-mass aliphatic polycations that are ubiquitously distributed in all living organisms (Hussain et al. 2011). They are known to be essential for growth and development in prokaryotes and eukaryotes (Tabor and Tabor 1984, Tiburcio et al. 1990). PAs have been implicated in various processes associated with plant growth and development, such as embryogenic competence (Silveira et al. 2013), programmed cell death (Kim et al. 2013), fruit ripening (Gil-Amado and GomezJimenez 2012), xylem differentiation (Tisi et al. 2011), as well as biofilm formation (Lee et al. 2009). Besides this, PAs elicit diverse physiological responses, including tuber

\section{Materials and methods}

Hormone preparation: The stock solution (1 M) of salicylic acid (SA) or spermidine (Spd) were prepared by dissolving the $13.812 \mathrm{~g}(\mathrm{SA})$ and $14.525 \mathrm{~g}(\mathrm{Spd})$ in $5 \mathrm{~mL}$ of ethanol, in 100-mL volumetric flasks and the final volume was made up to the mark by using double distilled water (DDW). The required concentrations of SA $\left(10^{-5} \mathrm{M}\right)$ or Spd $(1 \mathrm{mM})$ were prepared by the dilution of stock solution with DDW and these concentrations were selected on the basis of our previous studies by Fariduddin et al. (2003) and Mir et al. (2015), respectively. Tween-20 (0.5\%) was added to the solution prior to the treatment.

Experimental design: Surface-sterilized seeds were sown in nursery beds in a sandy-loam soil and cow manure (6:1, $\mathrm{v} / \mathrm{v})$ mixed under natural environmental conditions. Nursery beds were irrigated on alternate days with tap water. At 20-d stage, seedlings were uprooted and transplanted to earthen pots $(25 \mathrm{~cm}$ in diameter) filled with sandy-loam soil and cow manure $(6: 1, \mathrm{v} / \mathrm{v})$ under natural environmental conditions in the net house of Department of Botany, Aligarh Muslim University, Aligarh, India. After $30 \mathrm{~d}$ from sowing (DAS), plants were exposed to $\mathrm{NaCl}(200 \mathrm{mM})$ through soil and then allowed to grow till 45 DAS. These plants were sprayed with DDW (control), SA $\left(10^{-5} \mathrm{M}\right), \operatorname{Spd}(1 \mathrm{mM})$, or SA + Spd for three days. Each plant was sprinkled thrice and the nozzle of the sprayer was adjusted in such a way that it pumped out $c a .1 \mathrm{~mL}$ in one sprinkle. Each treatment included five pots (replicates) and in each pot three plants were maintained after thinning under a completely randomized block design. At 60 DAS, plants from each treatment were harvested to assess the formation, root initiation, embryogenesis, flower development, fruit ripening, organogenesis, and biotic and abiotic stress responses (Gil-Amado and Gomez-Jimenez 2012, Silveira et al. 2013, Mir et al. 2015). PAs have been involved in various protective responses in the cell (Pothipongsa et al. 2012, Tanou et al. 2012, 2014), which include strengthening of membranes and other macromolecules, which are targets of ROS damage. It has been suggested that PAs play pivotal roles in modulating defense response of plants to diverse environmental stresses (Bouchereau et al. 1999), which include metal toxicity (Groppa et al. 2003), oxidative stress (Rider et al. 2007), drought (Yamaguchi et al. 2007), salinity (Duan et al. 2008, Mir et al. 2015), and chilling stress (Groppa and Benavides 2008). In addition to this, it has been reported that exogenous application of PA under various abiotic stresses is also an effective approach for enhancing stress tolerance and productivity of crops. The present study was executed with an objective to study the impact of combined application of salicylic acid and spermidine to the salt-stressed plants of Lycopersicon esculentum and to elucidate how these compounds trigger antioxidant system leading to tolerance against salinity.

various growth and biochemical parameters and photosynthetic attributes.

Plant growth analysis: The plants were removed from the pots along with the soil and were dipped in a bucket filled with water. The plants were moved smoothly to remove the adhering soil particles and the lengths of shoots and roots were measured by using a meter scale. The plants were blotted and weighed to record their shoot and root fresh mass (FM) and then placed in an oven at $70^{\circ} \mathrm{C}$ for $72 \mathrm{~h}$. The samples were weighed again after allowing them to cool at room temperature to record their root and shoot dry mass (DM). The leaf area was measured by using a leaf area meter (ADC Bioscientific, UK).

Leaf water potential: The leaf water potential (LWP) was monitored with the Psypro water potential system (Wescor, Inc. South Logan, Utah, USA) in the third fully expanded leaves of the plant.

SPAD chlorophyll: The SPAD value of Chl was measured by using the SPAD Chl meter (SPAD-502; Konica, Minolta Sensing Inc., Japan) in the third fully expanded leaves of the plant.

Gas-exchange parameters were determined on the third fully expanded leaves between 11:00 and 12:00 h by using an infrared gas analyzer portable photosynthetic system (LI-COR 6400, LI-COR, Lincoln, NE, USA). To measure net photosynthetic rate $\left(P_{\mathrm{N}}\right)$ and its related attributes [stomatal conductance $\left(g_{\mathrm{s}}\right)$, internal $\mathrm{CO}_{2}$ concentration 
$\left(C_{\mathrm{i}}\right)$, and transpiration rate $\left.(E)\right]$ the air temperature, relative humidity, $\mathrm{CO}_{2}$ concentration, and PPFD were maintained

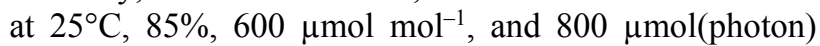
$\mathrm{mol}^{-2} \mathrm{~s}^{-1}$, respectively.

Electrolyte leakage: The total inorganic ions leaked out from leaves were estimated by the method of Sullivan and Ross (1979). Twenty leaf discs were taken in boiling tube containing $10 \mathrm{~mL}$ of deionized water and electrical conductivity was measured $\left(\mathrm{Ec}_{\mathrm{a}}\right)(P C-700$, Eutech Instruments, Thermo Scientific, Mumbai, India). The contents were heated at $45^{\circ} \mathrm{C}$ and $55^{\circ} \mathrm{C}$ for $30 \mathrm{~min}$ each in water bath and electrical conductivity was measured $\left(\mathrm{Ec}_{\mathrm{b}}\right)$. Later the content were again boiled at $100^{\circ} \mathrm{C}$ for $10 \mathrm{~min}$ and electrical conductivity $\left(\mathrm{Ec}_{\mathrm{c}}\right)$ was recorded again. The electrolyte leakage was calculated by using the formula.

$$
\text { Electrolyte leakage }[\%]=\frac{E c_{b}-E c_{a}}{E c_{c}} \times 100
$$

Carbonic anhydrase (CA): The activity of CA (EC 4.2.1.1) in the leaves was measured following the method described by Dwivedi and Randhawa (1974). The leaf samples were cut into small pieces in cysteine hydrochloride solution. These leaf samples were blotted and transferred in a test tube, followed by the addition of

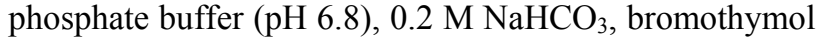
blue, and the methyl red indicator, at the last. The reaction was titrated against $0.05 \mathrm{~N} \mathrm{HCl}$. The activity of enzyme was expressed on the basis of fresh mass (FM) as mol $\left(\mathrm{CO}_{2}\right) \mathrm{g}^{-1}(\mathrm{FM}) \mathrm{s}^{-1}$.

Nitrate reductase (NR): The activity of NR (EC 1.7.1.1) was measured following the method of Jaworski (1971). The fresh leaf samples were cut into small pieces and transferred to plastic vials, containing phosphate buffer ( $\mathrm{pH} 7.5$ ), $\mathrm{KNO}_{3}$, and isopropanol, and then they were incubated at $30^{\circ} \mathrm{C}$ for $2 \mathrm{~h}$. After incubation, sulfanilamide and N-1-naphthylethylenediamine hydrochloride solutions were added. The absorbance was read at $540 \mathrm{~nm}$ on a spectrophotometer (Spectronic 20D, Milton Roy, USA). The activity of enzyme was expressed in on the basis of FM as $\mathrm{nM}\left(\mathrm{NO}_{2}\right) \mathrm{g}^{-1}(\mathrm{FM}) \mathrm{s}^{-1}$.

Antioxidative enzymes: The leaf tissue $(0.5 \mathrm{~g})$ was homogenized in $50 \mathrm{mM}$ phosphate buffer $(\mathrm{pH}$ 7.0) containing $1 \%(\mathrm{w} / \mathrm{v})$ soluble polyvinylpyrrolidone. The homogenate was centrifuged at 27,600 $\times g$ for $10 \mathrm{~min}$ at $4^{\circ} \mathrm{C}$ and the supernatant was used as source of enzymes

\section{Results}

Growth biomarkers: The plants raised in the soil supplemented with $200 \mathrm{mM}$ of $\mathrm{NaCl}$ showed a significant decrease in the values of all the growth biomarkers (root and shoot length, root and shoot FM, and DM) in catalase, peroxidase, and superoxide dismutase.

Peroxidase (POX, EC 1.11.1.7) and catalase (CAT, EC 1.11.1.6) were assayed following the procedure described by Chance and Maehly (1955). CAT was estimated by titrating the reaction mixture, consisting of phosphate buffer ( $\mathrm{pH} 6.8$ ), $0.1 \mathrm{M} \mathrm{H}_{2} \mathrm{O}_{2}$, enzyme extract, and $2 \%$ $\mathrm{H}_{2} \mathrm{SO}_{4}$, against $0.1 \mathrm{~N}$ potassium permanganate solution. The activity of enzyme was expressed on the basis of FM as $\mathrm{nM}\left(\mathrm{H}_{2} \mathrm{O}_{2}\right.$ decomposed $) \mathrm{g}^{-1}(\mathrm{FM})$.

The reaction mixture for POX consisted of pyrogallol, phosphate buffer ( $\mathrm{pH} 6.8$ ), $1 \% \mathrm{H}_{2} \mathrm{O}_{2}$, and enzyme extract. The change in absorbance due to catalytic conversion of pyrogallol to perpurogalline was noted at an interval of $20 \mathrm{~s}$ for $2 \mathrm{~min}$, at $420 \mathrm{~nm}$ by a spectrophotometer (Spectronic 20D, Milton Roy, USA). A control set was prepared by using double distilled water instead of enzyme extract. The activity of enzyme was expressed on the FM basis as $\mathrm{U} \mathrm{g}^{-1}(\mathrm{FM})$.

The activity of superoxide dismutase (SOD, EC 1.15.1.1) was assayed by measuring its ability to inhibit the photochemical reduction of nitroblue tetrazolium using the method of Beauchamp and Fridovich (1971). The reaction mixture contained $50 \mathrm{mM}$ phosphate buffer ( $\mathrm{pH} 7.8$ ), $13 \mathrm{mM}$ methionine, $75 \mathrm{mM}$ nitroblue tetrazolium (NBT), $2 \mathrm{mM}$ riboflavin, $0.1 \mathrm{mM}$ EDTA, and $50 \mu \mathrm{L}$ of enzyme extract and was placed under $15-\mathrm{W}$ fluorescent lamp (Philips Pvt Ltd, India). The reaction was started by switching on the light and was allowed to run for $10 \mathrm{~min}$. The reaction was stopped by switching off the light. Fifty percent inhibition under light was considered as one enzyme unit. The activity of enzyme was expressed on the basis of FM as $\mathrm{U} \mathrm{g}^{-1}$ (FM).

Proline accumulation: The proline content in fresh leaf samples was determined by adopting the method of Bates et al. (1973). Proline was extracted in 3\% sulphosalicylic acid. In the extract, an equal volume of glacial acetic acid and ninhydrin solutions were added. The sample was heated at $100^{\circ} \mathrm{C}$, to which $5 \mathrm{~mL}$ of toluene was added after cooling. The absorbance of the toluene layer was read at $520 \mathrm{~nm}$, by a spectrophotometer (Spectronic 20D, Milton Roy, USA).

Statistical analysis: Data were statistically analyzed using SPSS, 17.0 for Windows (SPSS, Chicago, IL, USA). Analysis of variance (ANOVA) was performed on the data to determine the least significant difference (LSD) between treatment means with the level of significance at $p \leq 0.05$.

comparison to control plants (Fig. 1). The spray of Spd $(1.0 \mathrm{mM}) \mathrm{and} /$ or SA $\left(10^{-5} \mathrm{M}\right)$ to the foliage of stress-free plants significantly increased all the growth markers. The combination of Spd and SA, increased the shoot and root 


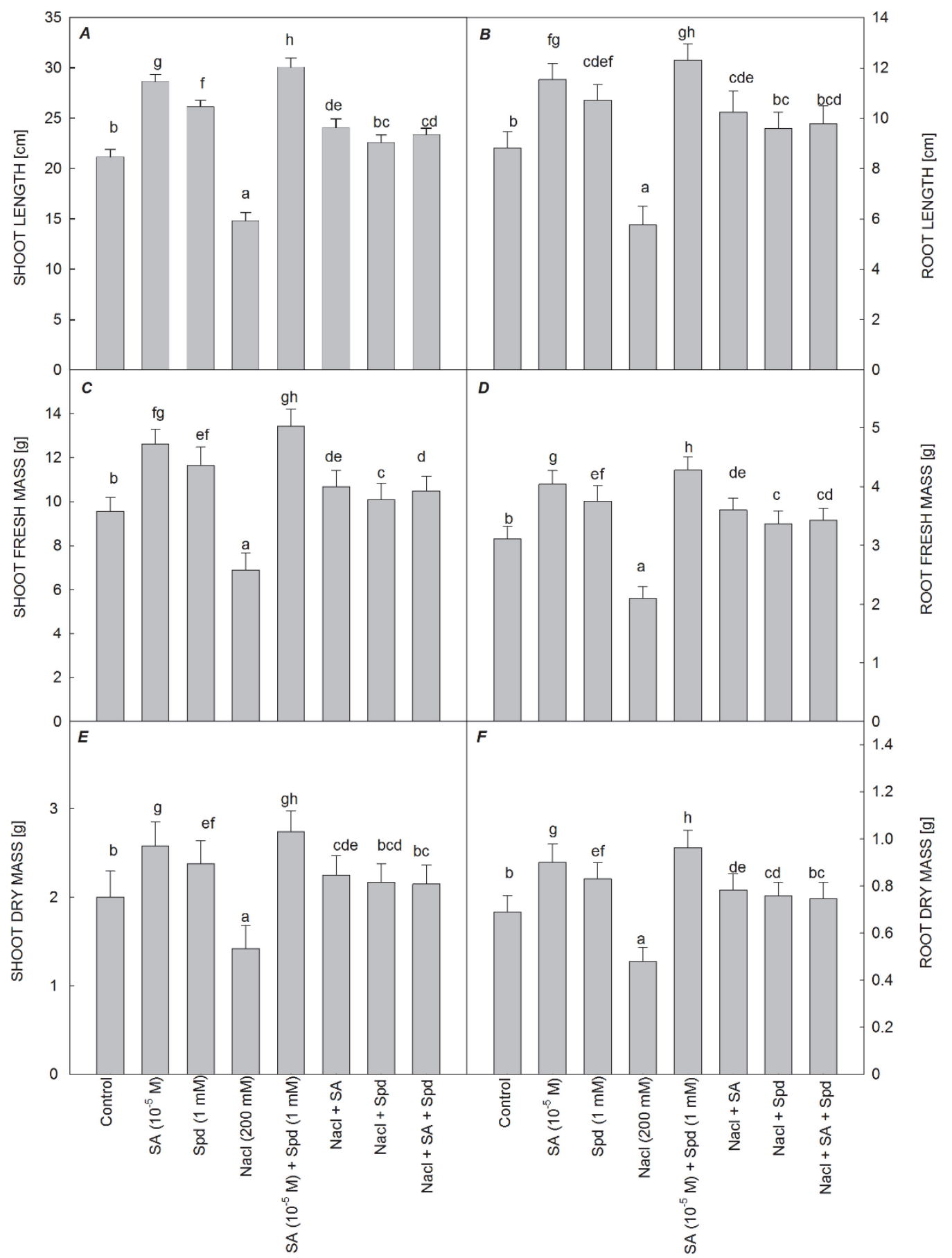

Fig. 1. Effect of salicylic acid $\left(\mathrm{SA} ; 10^{-5} \mathrm{M}\right)$ and/or spermidine $(\mathrm{Spd} ; 1 \mathrm{mM})$ on the salinity $(\mathrm{NaCl} ; 200 \mathrm{mM})$ induced changes in the $(A)$ shoot length, $(B)$ root length, $(C)$ shoot fresh mass, $(D)$ root fresh mass, $(E)$ shoot dry mass, and $(F)$ root dry mass in tomato at 60 days after sowing. All the data are the means of five replicates $(n=5)$; vertical bars show standard errors $( \pm$ SE). Means with different letters above the bars are significantly different between the treatments.

length by 40 and $42 \%$, respectively, DM of roots and shoots by 39 and $37 \%$, respectively, compared with the control plants. Moreover, the stressed plants treated with $\mathrm{SA}+$ Spd completely recovered from the damaging effects generated by $200 \mathrm{mM}$ of $\mathrm{NaCl}$.

Leaf area: The leaf area of the plants was significantly affected by the presence of $\mathrm{NaCl}$ and a decrease $(32 \%$ lesser area than that of the control) was noted at 60 DAS (Fig. 2A). The foliar application of SA and Spd alone improved the leaf area, compared with the control. The treatment of SA and Spd to the NaCl-treated plants completely recovered the loss of leaf area in comparison to stressed plants. 


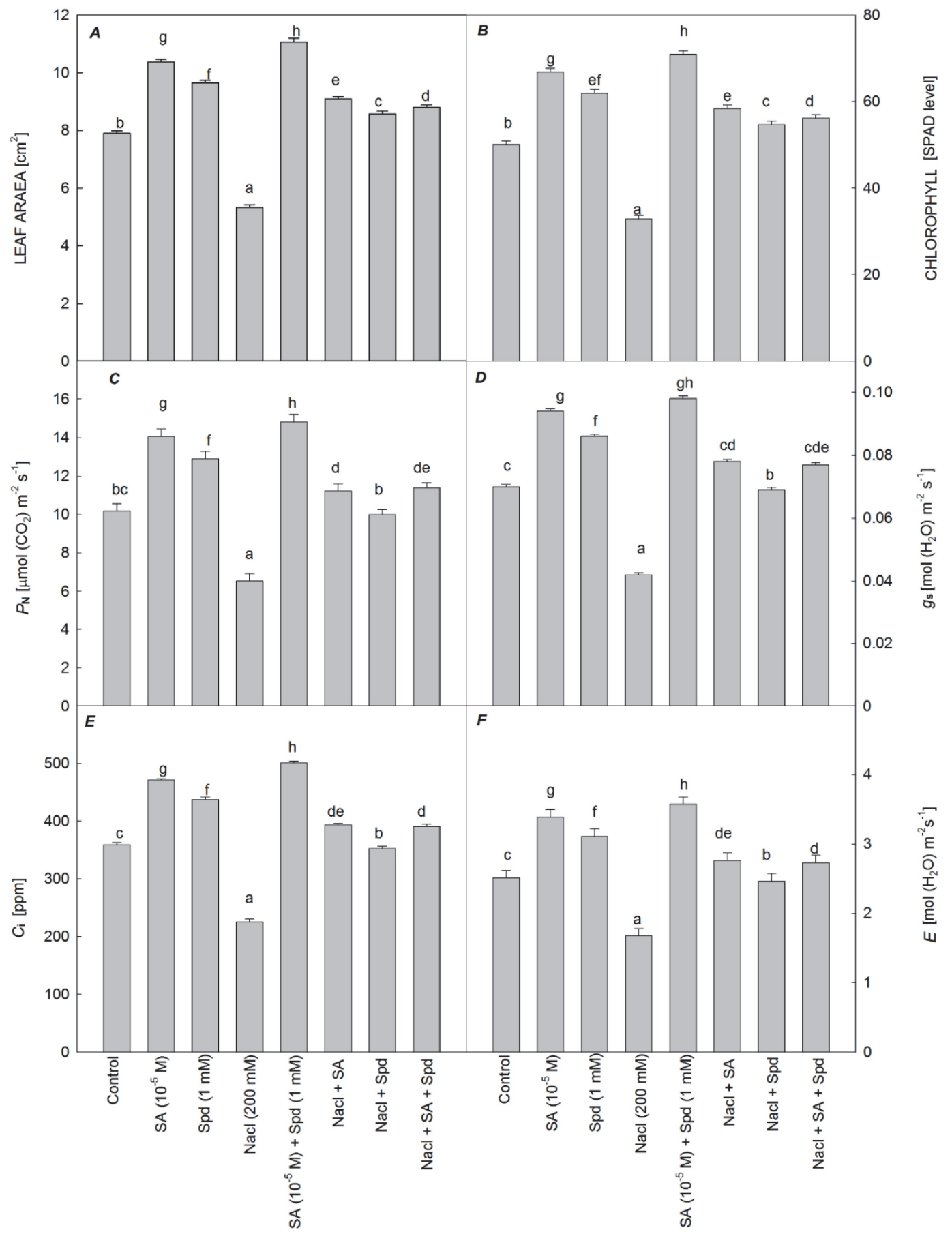

Fig. 2. Effect of salicylic acid $\left(\mathrm{SA} ; 10^{-5} \mathrm{M}\right)$ and/or spermidine $(\mathrm{Spd} ; 1 \mathrm{mM})$ on the salinity $(\mathrm{NaCl} ; 200 \mathrm{mM})$ induced changes in the $(A)$ leaf area, $(B)$ SPAD chlorophyll, $(C)$ net photosynthetic rate $\left(P_{\mathrm{N}}\right),(D)$ stomatal conductance $\left(g_{\mathrm{s}}\right),(E)$ intercellular $\mathrm{CO}_{2}$ concentration $\left(C_{\mathrm{i}}\right)$, and $(F)$ transpiration rate $(E)$ in tomato at 60 days after sowing. All the data are the means of five replicates $(n=5)$; vertical bars show standard errors $( \pm \mathrm{SE})$. Means with different letters above the bars are significantly different between the treatments.

Leaf water potential increased significantly in the plants treated with Spd and/or SA at 60 DAS (Fig. $3 A$ ). However, the combined effect of Spd+SA proved to be more efficient and increased the LWP by $36 \%$ in plants at 60 DAS, when compared with their respective controls. Moreover, the loss of LWP caused by $\mathrm{NaCl}$ was successfully restored by the following treatment by Spd and SA at 60 DAS.
SPAD Chl: Among various treatments, foliar application of SA and Spd alone and in combination (SA+Spd) significantly increased the Chl content (SPAD value) by 33,23 , and $41 \%$, respectively, compared with the control plants (Fig. 2B). However, the soil treated with $\mathrm{NaCl}$ significantly decreased the SPAD value of $\mathrm{Chl}$ in comparison with the control plants. Moreover, $\mathrm{NaCl}-$ 
induced decline was completely overcome with the combined SA+Spd treatment.

Photosynthesis and related attributes: $P_{\mathrm{N}}, g_{\mathrm{s}}, C_{\mathrm{i}}$, and $E$ were significantly reduced by the treatment of $\mathrm{NaCl}$ in comparison with the control plants (Fig. $2 C-F$ ). The the values of $P_{\mathrm{N}}$ were reduced by $36 \%, g_{\mathrm{s}}$ by $43 \%, C_{\mathrm{i}}$ by $37 \%$, and $E$ by $33 \%$ as compared with the control. The application of of both $\mathrm{SA}+\mathrm{Spd}$ to the plants significantly increased the value of $P_{\mathrm{N}}(45 \%)$ and $g_{\mathrm{s}}(29 \%), C_{\mathrm{i}}(39 \%)$, and $E(42 \%)$ compared with the control. However, NaClstressed plants treated with the $\mathrm{SA}+\mathrm{Spd}$ completely neutralized the toxic effect generated by $\mathrm{NaCl}$.

Activities of NR and CA: The plants exposed to $\mathrm{NaCl}$ stress possessed significantly lower activities of $\mathrm{CA}$ and NR than their respective control plants (Fig. 3B,C).
However, the application of Spd or SA alone or SA+Spd to the foliage of nonstressed plants significantly increased the activity of CA by 19,27 , and $32 \%$, respectively, and NR by 25,17 , and $30 \%$, respectively, at 60 DAS. Furthermore, the application of SA and Spd to the foliage of salt-stressed plants completely nullified the toxic effect of $\mathrm{NaCl}$.

Antioxidant enzymes: The activities of antioxidant enzymes (CAT, POX, and SOD) significantly increased in response to various treatments, compared with the control plants (Fig. 3). The foliar application of SA to the NaCltreated plants had an additive effect on the activities of these enzymes. The highest values for CAT, POX, and SOD were noted in the $\mathrm{NaCl}$-treated plants and also after the treatment by SA and Spd; and their activities were higher by 72 , 85 , and $69 \%$, respectively, compared with the control.

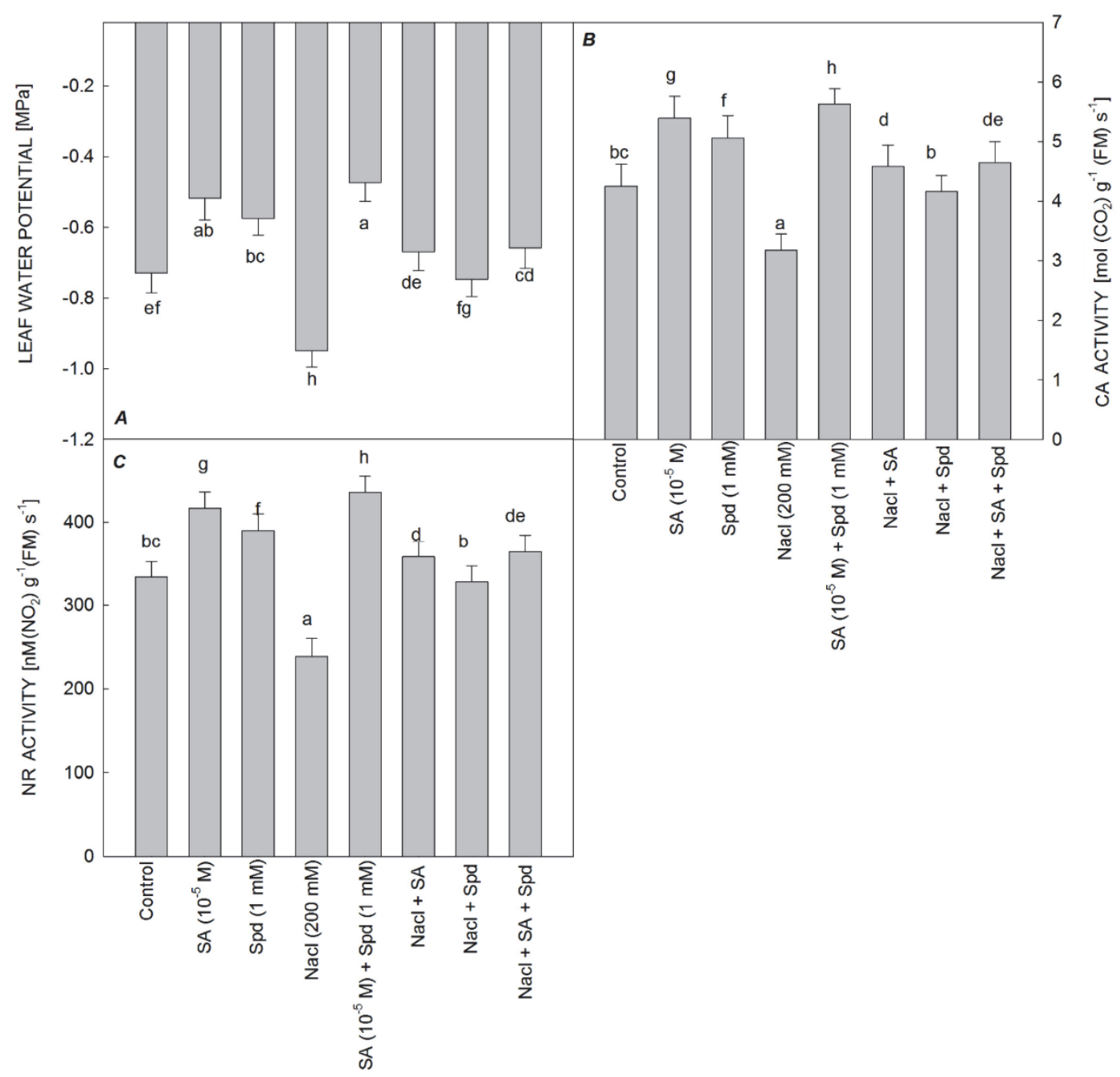

Fig. 3. Effect of salicylic acid $\left(\mathrm{SA} ; 10^{-5} \mathrm{M}\right)$ and/or spermidine $(\mathrm{Spd} ; 1 \mathrm{mM})$ on the salinity $(\mathrm{NaCl} ; 200 \mathrm{mM})$ induced changes in the $(A)$ leaf water potential, $(B)$ carbonic anhydrase $(\mathrm{CA})$, and $(C)$ nitrate reductase $(\mathrm{NR})$ in tomato at 60 days after sowing. All the data are the means of five replicates $(n=5)$; vertical bars show standard errors $( \pm \mathrm{SE})$. Means with different letters above the bars are significantly different between the treatments. 


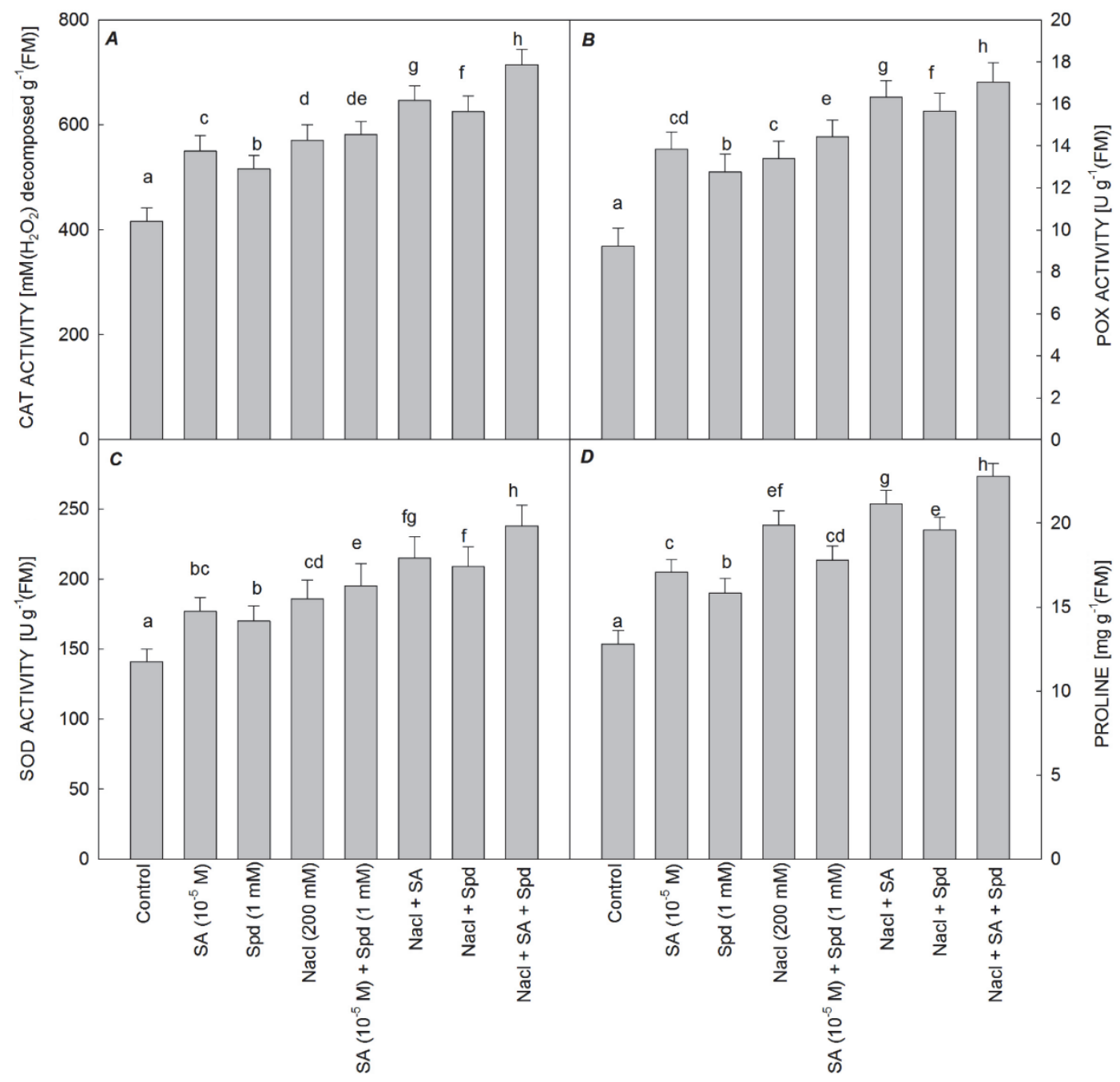

Fig. 4. Effect of salicylic acid $\left(\mathrm{SA} ; 10^{-5} \mathrm{M}\right)$ and/or spermidine $(\mathrm{Spd} ; 1 \mathrm{mM})$ on the salinity $(\mathrm{NaCl} ; 200 \mathrm{mM})$ induced changes in the $(A)$ catalase (CAT), $(B)$ peroxidase (POX), $(C)$ superoxide dismutase (SOD), and $(D)$ proline content in tomato at 60 days after sowing. All the data are the means of five replicates $(n=5)$; vertical bars show standard errors ( \pm SE). Means with different letters above the bars are significantly different between the treatments.

Proline content in leaves was elevated by all the treatments as compared with their respective control (Fig. 3D). The values of proline increased by 33, 24, and $55 \%$, respectively, in comparison with the respective control, in plants treated with $\mathrm{SA}, \mathrm{Spd}$ or $\mathrm{NaCl}$. The

\section{Discussion}

Salinity limits crop production in arid and semiarid regions and under soil moisture deficiency. Salinity of soil or irrigation water is the major limiting factor for crop growth in many regions of the world (Ashraf et al. 2008, Kausar et al. 2013). Salt stress at any stage of crop growth can cause an irreversible loss in a yield potential (Hameed et al. 2013) of many crops including tomato. In the present study, all growth parameters were significantly lowered in the plants exposed to salinity stress. Our results were in agreement with that of Wani et al. (2016) and Pirasteh- following treatment both $\mathrm{SA}+\mathrm{Spd}$ further increased the proline content. The maximum accumulation of proline was $78 \%$ higher than that of the control in the plants grown in $\mathrm{NaCl}$ supplemented soil.

Anosheh et al. (2014) who reported marked reduction in growth parameters of Brassica juncea and Hordeum vulgare subjected to $\mathrm{NaCl}$ stress. Growth inhibition by salinity has been attributed to the disturbance in water and osmotic potential, toxicity of excessive $\mathrm{Na}^{+}$and $\mathrm{Cl}^{-}$, disturbance in the accumulation of nutrients, disruption in the structure and the activity of the enzymes, damage in cell organelles and plasma membrane, disturbances in photosynthesis, respiration, and protein synthesis (Feng et al. 2002, Munns 2005). Salt-stress tolerance in crop plants 
is generally accompanied by low uptake and accumulation of $\mathrm{Na}^{+}$(Hameed et al. 2013), a cation that has been shown to have antagonistic effects on crops due to its toxic effects (Ouerghi et al. 2000). Therefore, $\mathrm{Na}^{+}$concentration in plant tissues could be used as an important indicator for salinity tolerance (Tadayon and Emam 2007). However, the subsequent application of SA and/or Spd was beneficial to sustain the growth and reduce deleterious effects of salt stress (Fig. 1). The stressed plants treated with SA or Spd increased their FM and DM as well as root and shoot length and leaf area, compared with those grown without SA or Spd (Figs. 1, 2A). A similar increase by SA treatment has been reported by Yusuf et al. (2008). However, Mimouni et al. (2016) reported that SA-treated plants had greater shoot and root dry mass, leaf area compared with untreated plants when exposed to salt stress. The combination of SA (Parashar et al. 2014) and PA (Benavides et al. 1997, Duan et al. 2008, Mir et al. 2015) are known to improve the growth of root and/or shoot in various plant groups. The increase in the growth parameters caused by SA is due to the regulation of cell cycle (Carswell et al. 1989) and might be due to a negative balance of leaf xylem import and phloem export process after the modification of leaf soluble salt during recovery (DeLacerda et al. 2005). It appears that a large amount of ions absorbed during stress might be transferred to young leaves after recovery (Alarcon et al. 1993). Furthermore, the involvement of PA, in wide array of plant processes, such as DNA replication, transcription of genes, cell division, and root growth (Bais and Ravishankar 2002), are responsible for the growth improvement. The enhanced tolerance to salt stress may be due to involvement of PA in the maintenance of tonoplast $\mathrm{H}^{+}$-ATPase, protontranslocating inorganic pyrophosphatases $\left(\mathrm{H}^{+}-\mathrm{PPase}\right)$, and $\mathrm{Na}^{+} / \mathrm{H}^{+}$transporter (Liu et al. 2006). Spd functions as membrane surface stabilizers through interaction with phospholipids or other negatively charged groups of membrane (Amri and Shahsavar 2010). It is interesting to observe that co-application of SA and Spd proved to be more effective in the improvement of growth parameters under salt stress, perhaps, it could be due to their synergistic or additive effects.

In addition to the primary effects, salinity inevitably leads to oxidative stress through an increase in ROS, such as superoxide anion $\left(\mathrm{O}_{2}{ }^{-}\right)$, hydrogen peroxide $\left(\mathrm{H}_{2} \mathrm{O}_{2}\right)$, and hydroxyl radicals $\left(\mathrm{OH}^{*}\right)$ (Zheng et al. 2009). It is now widely accepted that these cytotoxic ROS are responsible for various stress-induced damages to macromolecules and ultimately to cellular structure (Amor et al. 2006, Sekmen et al. 2012). ROS detoxification by enzymatic (SOD, CAT, and POX) antioxidants is the effective defence mechanism against oxidative damage in plants (Verslues et al. 2006, Khan and Panda 2008). In the present study, we observed higher activities of CAT, POX, and SOD, as well as the proline content in the plants exposed to $\mathrm{NaCl}$ stress with or without SA and/or Spd treatments (Fig. 4). SA conferred protection against salinity in tomato plants probably by improving the activity of aldose reductase and APX enzymes and through the accumulation of osmolytes, e.g., sugar alcohol or proline (Tari et al. 2002, Szepesi et al. 2005). Proteomic study also revealed that synthesis of antioxidant enzymes and the mobilization of seed storage proteins play pivotal role in SA-mediated salt tolerance (Rajjou et al. 2006). In addition to this, Chen and Dickman (2005) reported that proline is a potent scavenger of ROS and also a major component of structural proteins in plants, known to be osmoprotectant capable of mitigating the impacts of various abiotic stresses in plants (Szabados and Savowre 2009). Similarly, the application of Spd had been also shown to ameliorate $\mathrm{NaCl}$ stress in chickpea and Vigna radiata plants by elevating the activities of CAT, glutathione peroxidase, glutathione reductase, and SOD (Sheokand et al. 2008, Mir et al. 2015). Recently, Li et al. (2016) was reported that Spd also enhanced the CAT, POX, and SOD activity when exposed to salt stress in Zoysia japonica. Spd in particular increased the DNAbinding activity of transcription factors and promoted gene transcript levels (Childs et al. 2003). Sung et al. (2011) reported that Spd provided defence against hypersalinity through the upregulation of FeSOD gene, thereby improving oxidative stress damage. Our results validated the additive interactions of SA and Spd for amelioration of the oxidative stress generated by $\mathrm{NaCl}$.

Salt stress damages the photosynthetic machinery at multiple levels, such as pigment content, structure and function of thylakoids, electron transport and enzymes, stomatal functioning, and gas exchange (Geissler et al. 2009). Salinity causes a decrease in Chl content via the acceleration of Chl degradation or inhibition of its biosynthesis (Xu et al. 2000). The effect of these processes resulted in the decreased SPAD value of Chl as it was found in our study (Fig. 2B). Similar decrease in Chl content was observed by Hayat et al. (2012). These results are further supported by Wu et al. (2012), Wang et al. (2010), Ahmad et al. (2012a), and Wani et al. (2013, 2016). However, the subsequent treatment by SA and/or Spd improved the SPAD values. In the present study, SA treatment of nonstressed plants increased the Chl content; it was also reported by others (Parashar et al. 2014) and also well supported by the earlier observations in wheat and/or mung bean seedlings under stress-free conditions (Moharekar et al. 2003, Hayat et al. 2005) as well as under water stress (Singh and Usha 2003). Moreover, Spd treatment also increased the SPAD value. It was reported that Spd also increased the Chl content in rice and Vigna radiata (Krishnamurthy 1991, Mir et al. 2015). It could be due to the elevated concentration of $\mathrm{Mg}^{2+}$ (Lakra et al. 2006), which is essential for Chl synthesis. Salt stress caused the closure of stomata (Bethkey and Drew 1992), therefore, it decreased partial $\mathrm{CO}_{2}$ pressure and thus $C_{\mathrm{i}}, g_{\mathrm{s}}$, and consequently CA activity (Ali et al. 2008). Besides this, salinity impairs photosynthesis and the photosynthetic electron transport chain (Sudhir and Murthy 2004). All these impaired events finally resulted in a 
severe decline in $P_{\mathrm{N}}$ (Fig. $2 C$ ). The damage caused by salt stress could be also attributed to water stress or a kind of physiological drought generated by $\mathrm{NaCl}$ (Perez-López et al. 2009, Belkheiri and Mulas 2013) as evident from the decrease in leaf water potential in our present study (Fig. $3 A)$. Decrease in all gas-exchange parameters $\left(P_{\mathrm{N}}, g_{\mathrm{s}}, C_{\mathrm{i}}\right.$, and $E$ ) due to salinity has also been reported in Brassica juncea (Wani et al. 2013, 2016), and Vigna radiata (Hayat et al. 2010, Mir et al. 2015). Other reasons for the decrease in $P_{\mathrm{N}}$ under $\mathrm{NaCl}$ are faster senescence and changes in enzyme activities induced by dysfunction of proteins and negative feedback by reduced sink activity (Iyengar and Reddy 1996). SA is well-known as an important plant growth regulator involved in regulating stomatal closure, Chl content (Hussein et al. 2007, Parashar et al. 2014), net photosynthesis, and other physiological parameters, such as transpiration, glycolysis, uptake and transport of nutrients, membrane permeability, flowering and thermogenesis, and growth rate (Ashraf et al. 2010). SA has been established as an important regulator of photosynthesis, water relations, and metabolic aspects of plants, depending on its analogues, concentrations, mode of application and plant type. SA is known to affect leaf and chloroplast structure (Uzunova and Popova 2000), stomatal closure (Mateo et al. 2004, Melotto et al. 2006), Chl and carotenoid contents (Chandra and Bhatt 1998, Fariduddin et al. 2003), and the activity of enzymes, such as Rubisco and CA (Slaymaker et al. 2002, Parashar et al. 2014). Moreover, treatment of SA and/or Spd improved the gas-exchange parameters. Therefore, the plants treated with SA, both in presence and absence of stress, exhibited the higher $P_{\mathrm{N}}$ and related attributes. PAs are well recognized for their positive effects on photosynthetic efficacy under various stress conditions. Spd comprises of extremely protonated amino and imino groups and could be conjugated with other negatively charged organic molecules, such as proteins, nucleic acids, and phospholipids. The binding is important for the maintenance of the thylakoid membranes and avoidance of the hydrolysis of photosynthetic proteins (Ahmad et al. 2012b). In our present study, foliar application of Spd also resulted in physiological damage related with salinity, thus confirming previous observations that exogenous PAs significantly improved the physiological status of stressed plants (Sen et al. 2014, Tanou et al. 2014). Moreover, PAs play a role in retarding the loss of D1, D2, and cytochrome $f$ from the thylakoid membranes as well as large subunits of Rubisco and Chl from the leaf tissue (Besford et al. 1993). This could increase $P_{\mathrm{N}}$ in the present study. Spd application improved the CA activity by its involvement at

\section{References}

Agarwal S., Sairam F.K., Srivastava G.C. et al.: Role of ABA, salicylic acid, calcium and hydrogen peroxide on antioxidant enzymes induction in wheat seedlings. - Plant Sci. 169: 559$570,2005$. the level of transcription and/or translation (Cohen 1998) that might generate a significant impact on CA activity (Fig. 3B). Plants exposed to salinity exhibited lower activity of NR (Fig. 3C). This might be an after-effect of the inhibition and/or metabolic dysfunction of NR (Hopkins and Huner 2009). Moreover, stress factors interfere with the structure and fluidity of the membrane (Alia-Mohanty and Saradhi 1992, Karim et al. 1999) on exposure to salt stress. It might restrict the uptake of nitrate, the inducer and substrate for the NR (Campbell 1999) resulting in the decreased NR activity (Fig. 3C). However, treatment of SA and/or Spd to both stressed and nonstressed plants enhanced the activity of NR. The most appropriate reason to explain the SA-mediated elevation in the activity of NR is that it corrects the stress-mediated damage to the plasma membrane, as evident from an increase in the membrane stability index in wheat (Agarwal et al. 2005). The membrane correction/ stabilization could facilitate the increased uptake of nutrients including that of nitrate, which acts as an inducer of NR (Campbell 1999). The increase in the uptake of various nutrients, including $\mathrm{NO}_{3}$ and activation of $\mathrm{NR}$, under normal growth conditions is well established (Hayat et al. 2005) which strongly supports our present results. These results are further supported by Yusuf et al. (2008), Idrees et al. (2012), and Mir et al. (2015). Furthermore, Rosales et al. (2012) proposed that PAs could participate in the regulation of NR activity in a dual manner. At short time, PAs inhibit the NR activity by increasing NO production (a signaling molecule involved in the inhibition of NR activity) and 14-3-3 protein-master regulator of many signal transduction cascades and their interaction with NR (Athwal and Huber 2002). At longer time, PAs modulate the association of 14-3-3 proteins with the $\mathrm{H}^{+}$ATPase, thus activating NR activity, and this action could prevail over the effect of the increased NO concentration. The role of SA and PAs in restoring growth has been shown independently in several studies (Rady 2011, Parashar et al. 2014). It is apparent that both plant growth regulators (SA and PA) crosstalk to induce defensive genes countering stress conditions.

Conclusions: Salt stress decreased the growth, physiological, and biochemical parameters in L. esculentum. Application of both $\mathrm{SA}+\mathrm{Spd}$ was more effective in alleviation of toxicity generated by excess $\mathrm{NaCl}$ than their individual effects. Our study further confirmed that treatment of plant with both SA and Spd at particular stage of growth could be exploited to overcome the loss of crop productivity due to presence of excess salt in soil

Ahmad P., Azooz M.M., Prasad M.N.V.: Ecophysiology and Responses of Plants under Salt Stress. Pp. 149-168. Springer Science \& Business Media, New York 2012b.

Ahmad P., Hakeem K.U.R., Kumar A. et al.: Salt induced 
changes in photosynthetic activity and oxidative defense system of three cultivars of mustard (Brassica juncea L.). Afr. J. Biotechnol. 11: 2694-2703, 2012a.

Ahmad P., Jaleel C.A., Azooz M.M. et al.: Generation of ROS and non-enzymatic antioxidants during abiotic stress in plants. - Bot. Res. Intern. 2: 11-20, 2009.

Alarcon J.J., Sanchez-Blanco M.J., Bolarin M.C. et al.: Water relation and osmotic adjustment in Lycopersicum esculentum and L. pinnelli during short-term of salt exposure and recovery. - Physiol. Plantarum 89: 441-447, 1993.

Al-Hakimi A.M.A., Hamada A.M.: Counteraction of salinity stress on wheat plants by grain soaking in ascorbic acid, thiamin or sodium salicylate. - Biol. Plantarum 44: 253-261, 2001.

Ali Q., Athar H.R., Ashraf M.: Modulation of growth, photosynthetic capacity and water relations in salt stressed wheat plants by exogenously applied 24-epibrassinolide. - Plant Growth Regul. 56: 107-116, 2008.

Alia, Mohanty P., Saradhi P.P.: Effect of sodium chloride on primary photochemical activities in cotyledonary leaves of Brassica juncea. - Biochem. Physiol. 188: 1-12, 1992.

Amor N.B., Jiménez A., Megdiche W. et al:: Response of antioxidant systems to $\mathrm{NaCl}$ stress in the halophyte Cakile maritima. - Physiol. Plantarum 126: 446-457, 2006.

Amri E., Shahsavar A.: Response of lime seedlings (Citrus aurantifolia L.) to exogenous spermidine treatments under drought stress. - Aust. J. Basic Appl. Sci. 4: 4483-4489, 2010.

Arfan M., Athar H.R., Ashraf M.: Does exogenous application of salicylic acid through the rooting medium modulate growth and photosynthetic capacity in two differently adapted spring wheat cultivars under salt stress? - J. Plant Physiol. 164: 685-694, 2007.

Ashraf M., Akram N.A., Arteca R.N. et al.: The physiological, biochemical and molecular roles of brassinosteroids and salicylic acid in plant processes and salt tolerance. - Crit. Rev. Plant Sci. 29: 162-190, 2010.

Ashraf M., Athar H.R., Harris P.J.C. et al.: Some prospective strategies for improving crop salt tolerance. - Adv. Agron. 97: 45-110, 2008.

Athwal G.S., Huber S.C.: Divalent cations and polyamines bind to loop 8 of 14-3-3 proteins, modulating their interaction with phosphorylated nitrate reductase. - Plant J. 29: 119-129, 2002.

Bais H.P., Ravishankar G.A.: Role of polyamines in the ontogeny of plants and their biotechnological applications. - Plant Cell Tiss. Org. 69: 1-34, 2002.

Bates L.S., Waldeen R.P., Teare I.D.: Rapid determination of free proline for water stress studies. - Plant Soil 39: 205-207, 1973.

Beauchamp C.O., Fridovich I.: Superoxide dismutase: improved assays and assays applicable to acrylamide gels. - Anal. Biochem. 44: 276-287, 1971.

Belkheiri O., Mulas M.: The effects of salt stress on growth, water relations and ion accumulation in two halophyte Atriplex species. - Environ. Exp. Bot. 86: 17-28, 2013.

Benavides M.P., Aizencang G., Tomaro M.L.: Polyamines in Helianthus annuus L. during germination under salt stress. - J. Plant Growth Regul. 16: 205-211, 1997.

Besford R.T., Richardson C.M., Campos J.L. et al:: Effect of polyamines on stabilization of molecular complexes in thylakoid membranes of osmotically stressed oat leaves. Planta 189: 201-206, 1993.

Bethkey P.C., Drew M.C.: Stomatal and non-stomatal components to inhibition of photosynthesis in leaves of Capsicum annum during progressive exposure to $\mathrm{NaCl}$ salinity.
- Plant Physiol. 99: 219-226, 1992.

Bouchereau A., Azis A., Larher F. et al: Polyamines and environmental challenges: recent development. - Plant Sci. 140: 103-125, 1999.

Campbell H.W.: Nitrate reductase structure, function and regulation: Bridging the gap between biochemistry and physiology. - Annu. Rev. Plant Phys. 50: 277-303, 1999.

Carswell G.K., Johnson C.M, Shillito R.D. et al.: $O$-acetylsalicylic acid promotes colony formation from protoplasts of an elite maize inbred. - Plant Cell Rep. 8: 282-284, 1989.

Chance B., Maehly A.C.: Assay of catalase and peroxidases. Method. Enzymol. 2: 764-775, 1955.

Chandra A., Bhatt R.K.: Biochemical and physiological response to salicylic acid in relation to the systemic acquired resistance. - Photosynthetica 35: 255-258, 1998.

Chen C., Dickman M.B.: Proline suppresses apoptosis in the fungal pathogen Colletotrichum trifolii. - P. Natl. Acad. Sci. USA 102: 3459-3464, 2005.

Childs A.C., Mehta D.J., Germer E.W.: Polyamine-dependent gene expression. - Cell Mol. Life. Sci. 60: 1394-1406, 2003.

Cohen S., Frank E., Doyle W.J. et al.: Types of stressors that increase susceptibility to the common cold in healthy adults. Health Psychol. 17: 214-223, 1998.

DeLacerda C.F., Cambraia J., Oliva M.A. et al.: Changes in growth and in solute concentrations in sorghum leaves and roots during salt stress recovery. - Environ. Exp. Bot. 54: 69$76,2005$.

Duan J.J., Li J., Guo S.R. et al:: Exogenous spermidine affects polyamine metabolism in salinity-stressed Cucumis sativus roots and enhances short-term salinity tolerance. - J. Plant Physiol. 165: 1620-1635, 2008.

Dwivedi R.S., Randhawa N.S.: Evolution of a rapid test for the hidden hunger of zinc in plants. - Plant Soil 40: 445-451, 1974.

Fariduddin Q., Hayat S., Ahmad A.: Salicylic acid influences net photosynthetic rate, carboxylation efficiency, nitrate reductase activity and seed yield in Brassica juncea. - Photosynthetica 41: 281-284, 2003.

Feng G., Zhang F.S., Li X.L. et al.: Improved tolerance of maize plants to salt stress by arbuscular mycorrhiza is related to higher accumulation of soluble sugars in roots. - Mycorrhiza 12: 185-190, 2002.

Geissler N., Hussin S., Koyro H.W.: Elevated atmospheric $\mathrm{CO}_{2}$ concentration ameliorates effects of $\mathrm{NaCl}$ salinity on photosynthesis and leaf structure of Aster tripolium L. - J. Exp. Bot. 60: 137-151, 2009.

Gil-Amado J.A., Gomez-Jimenez M.C.: Regulation of polyamine metabolism and biosynthetic gene expression during olive mature-fruit abscission. - Planta 235: 1221-1237, 2012.

Groppa M.D., Benavides M.P., Tomaro M.L.: Polyamine metabolism in sunflower and wheat leaf discs under cadmium or copper stress. - Plant Sci. 164: 293-299, 2003.

Groppa M.D., Benavides M.P.: Polyamines and abiotic stress: recent advances. - Amino Acids 34: 35-45, 2008.

Hameed M., Nawaz T., Ashraf M. et al.: Physioanatomical adaptations in response to salt stress in Sporobolus arabicus (Poaceae) from the Salt Range, Pakistan. - Turk. J. Bot. 37: 715-724, 2013.

Hayat S., Fariduddin Q., Ali B. et al.: Effect of salicylic acid on growth and enzyme activities of wheat seedlings. - Acta Agron. Hung. 53: 433-437, 2005.

Hayat S., Hasan S.A., Yusuf M. et al:: Effect of 28-homobrassinolide on photosynthesis, fluorescence and antioxidant system in the presence or absence of salinity and temperature 
in Vigna radiata. - Environ. Exp. Bot. 69: 105-112, 2010.

Hayat S., Maheshwari P., Wani A.S. et al.: Comparative effect of homobrassinolide and salicylic acid in the amelioration of $\mathrm{NaCl}$ stress in Brassica juncea L. - Plant Physiol. Bioch. 53: 61-68, 2012.

He Y.L., Liu Y., Chen Q. et al.: Thermotolerance related to antioxidation induced by salicylic acid and heat acclimation in tall fescue seedlings. - J. Plant Phys. 28: 89-95, 2002.

Hopkins W.G., Hüner N.P.A.: Introduction to Plant Physiology. Pp. 503. John Wiley \& Sons, Inc., Hoboken 2009.

Hussain S.S., Ali M., Ahmad M. et al.: Polyamines: natural and engineered abiotic and biotic stress tolerance in plants. Biotechnol. Adv. 29: 300-311, 2011.

Hussein M.M., Balbaa L.K., Gaballah M.S.: Salicylic acid and salinity effects on growth of maize plants. - J. Agric. Biol. Sci. 3: 321-328, 2007.

Idrees M., Naeem M., Khan M.N. et al.: Alleviation of salt stress in lemongrass by salicylic acid. - Protoplasma 249: 709-720, 2012.

Iyengar E.R.R., Reddy M.P.: Photosynthesis in highly salt tolerant plants. - In: Pessarakli M. (ed.): Handbook of Photosynthesis. Pp. 897-909. Marcel Dekker, New York 1996.

Jaworski E.G.: Nitrate reductase assay in intact plant tissues. Biochem. Biophys. Res. Co. 43: 1274-1279, 1971.

Jayakannan M., Bose J., Babourina O. et al.: Salicylic acid in plant salinity stress signalling and tolerance. - Plant Growth Regul. 76: 25-40, 2015.

Karim M.A., Fracheboud Y., Stamp P.: Photosynthetic activity of developing leaves of Zea mays is less affected by heat stress than of developed leaves. - Physiol. Plantarum 105: 685-693, 1999.

Kausar F., Shahbaz M., Ashraf M. et al.: Protective role of foliar applied nitric oxide in Triticum aestivum under saline stress. Turk. J. Bot. 37: 1155-1165, 2013.

Khan M.H., Panda S.K.: Alterations in root lipid peroxidation and antioxidative responses in two rice cultivars under $\mathrm{NaCl}$ salinity stress. - Acta Physiol. Plant. 30: 81-89, 2008.

Khodary S.E.A.: Effect of salicylic acid on growth, photosynthesis and carbohydrate metabolism in salt stressed maize plants. - Int. J. Agric. Biol. 6: 5-8, 2004.

Kim N.H., Kim B.S., Hwang B.K.: Pepper arginine decarboxylase is required for polyamine and gamma-aminobutyric acid signaling in cell death and defense response. - Plant Physiol. 162: 2067-2083, 2013.

Koca M., Bor M., Özdemir F. et al.: The effect of salt stress on lipid peroxidation, antioxidative enzymes and proline content of Sesame cultivars. - Environ. Exp. Bot. 60: 344-351, 2007.

Krishnamurthy R.: Amelioration of salinity effect in salt tolerant rice (Oryza sativa L.) by foliar application of putrescine. Plant Cell Physiol. 32: 699-703, 1991.

Lakra N., Mishra S.N., Singh D.B. et al.: Exogenous putrescine effect on cation concentration in leaf of Brassica juncea seedlings subjected to $\mathrm{Cd}$ and $\mathrm{Pb}$ along with salinity stress. $-\mathrm{J}$. Environ. Biol. 27: 263-269, 2006.

Lee J., Sperandio V., Frantz D.E. et al.: An alternative polyamine biosynthetic pathway is widespread in bacteria and essential for biofilm formation in Vibrio cholerae. - J. Biol. Chem. 284: 9899-9907, 2009

Li S., Jin H., Zhang Q.: The effect of exogenous spermidine concentration on polyamine metabolism and salt tolerance in Zoysiagrass (Zoysia japonica Steud) subjected to short-term salinity stress. - Front. Plant Sci. 7: 1221, 2016.

Li T.X., Yue Z., Hua L. et al.: Stable expression of Arabidopsis vacuolar $\mathrm{Na}^{+} / \mathrm{H}^{+}$antiporter gene $A t N H X 1$ and salt tolerance in transgenic soybean for over six generations. - Chinese Sci. Bull. 55: 1127-1134, 2010.

Liu J., Zhou Y.F., Zhang W.H. et al.: Effects of exogenous polyamines on chloroplast-bound polymine content and photosynthesis of corn suffering salt stress. - Acta Bot. Boreal. 26: 254-258, 2006.

Manaa A., Gharbi E., Mimouni H. et al.: Simultaneous application of salicylic acid and calcium improves salt tolerance in two contrasting tomato (Solanum lycopersicum) cultivars. - South Afr. J. Bot. 95: 32-39, 2014.

Mateo A., Mühlenbock P., Rustérucci C. et al.: Lesion simulating disease 1 is required for acclimation to conditions that promote excess excitation energy. - Plant Physiol. 136: 2818-2830, 2004.

Melotto M., Underwood W., Koczan J. et al.: Plant stomata function in innate immunity against bacterial invasion. - Cell 126: 969-980, 2006.

Metwally A., Finkmemeier I., Georgi M. et al.: Salicylic acid alleviates the cadmium toxcity in barley seedlings. - Plant Physiol. 132: 272-281, 2003.

Mimouni H., Wasti S., Manaa A. et al.: Does salicylic acid (SA) improve tolerance to salt stress in plants? a study of SA effects on tomato plant growth, water dynamics, photosynthesis, and biochemical parameters. - OMICS 20: 180-190, 2016.

Mir B.A., Khan T.A., Fariduddin Q.: 24-epibrassinolide and spermidine modulate photosynthesis and antioxidant systems in Vigna radiata under salt and zinc stress. - Int. J. Adv. Res. 3: 592-608, 2015.

Mittler R.: Oxidative stress, antioxidants and stress tolerance. Trends Plant Sci. 7: 405-410, 2002.

Moharekar S.T., Lokhande S.D., Hara T. et al.: Effect of salicylic acid on chlorophyll and carotenoid contents of wheat and moong seedlings. - Photosynthetica 41: 315-317, 2003.

Munné-Bosch S.M., Peñuelas J., Llusià J.: A deficiency in salicylic acid alters isoprenoid accumulation in water stressed transgenic Arabidopsis plants. - Plant Sci. 172: 756-762, 2007.

Munns R.: Genes and salt tolerance: bringing them together. New Phytol. 167: 645-663, 2005.

Murphy K.S.T., Kinsey S.T., Durako M.J.: Physiological effects of short term salinity changes on Ruppia maritima. - Aquat Bot. 75: 293-309, 2003

Mutlu F., Bozcuk S.: Effects of salinity on the contents of polyamines and some other compounds in sunflower plants differing in salt tolerance. - Russ. J. Plant Physl+ 52: 29-34, 2005. Najafian S., Khoshkhui M., Tavallali V. et al.: Effect of salicylic acid and salinity in thyme (Thymus vulgaris L.): Investigation on changes in gas exchange, water relations, and membrane stabilization and biomass accumulation. - Aust. J. Basic Appl. Sci. 3: 2620-2626, 2009.

Ouerghi Z., Cornic G., Roudani M. et al.: Effect of $\mathrm{NaCl}$ on the photosynthesis of two wheat species differing in their sensitivity to salt stress. - J. Plant Physio. 156: 335-340, 2000.

Pál M.E., Horváth T., Janda E. et al.: Cadmium stimulates the accumulation of salicylic acid and its putative precursors in maize (Zea mays) plants. - Physiol. Plantarum 125: 356-364, 2005.

Parashar A., Yusuf M., Fariduddin Q. et al.: Salicylic acid enhances antioxidant system in Brassica juncea grown under different levels of manganese. - Int. J. Biol. Macromol. 70: 551-558, 2014

Pirasteh-Anosheh H., Ranjbar G., Emam Y. et al.: Salicylic-acidinduced recovery ability in salt-stressed Hordeum vulgare 
plants. - Turk. J. Bot. 38: 112-121, 2014.

Pothipongsa A., Jantaro S., Incharoensakdi A.: Polyamines induced by osmotic stress protect Synechocystis sp. PCC 6803 cells and arginine decarboxylase transcripts against UV-B radiation. - Appl. Biochem. Biotech. 168: 1476-1488, 2012.

Qadir M., Quillérou E., Nangia V. et al.: Economics of saltinduced land degradation and restoration. - Nat. Resour. Forum. 38: 282-295, 2014

Rady M.M.: Effect of 24-epibrassinolide on growth, yield, antioxidant system and cadmium content of bean (Phaseolus vulgaris $L$.) plants under salinity and cadmium stress. - Sci. Hortic.-Amsterdam 129: 232-237, 2011.

Rajjou L., Belghazi M., Huguet R. et al.: Proteomic investigation of the effect of salicylic acid on Arabidopsis seed germination and establishment of early defense mechanisms. - Plant Physiol. 141: 910-923, 2006.

Rider J.E., Hacker A., Mackintosh C.A et al.: Spermine and spermidine mediate protection against oxidative damage caused by hydrogen peroxide. - Amino Acids 33: 231-240, 2007.

Rosales E.P., Iannone M.F., Groppa M.D. et al.: Polyamines modulate nitrate reductase activity in wheat leaves: involvement of nitric oxide. - Amino Acids 42: 857-865, 2012.

Sekmen A.H., Turkan I, Tanyolac Z.O. et al.: Different antioxidant defense responses to salt stress during germination and vegetative stages of endemic halophyte Gypsophila oblanceolata Bark. - Environ. Exp. Bot. 77: 63-76, 2012.

Sen G., Eryilmaz I.E., Ozakca D.: The effect of aluminium-stress and exogenous spermidine on chlorophyll degradation, glutathione reductase activity and the photosystem II D1 protein gene $(p s b A)$ transcript level in lichen Xanthoria parietina. - Phytochemistry 98: 54-59, 2014.

Seneratna T., Touchell D., Bunn E. et al.: Acetyl salicylic acid (aspirin) and salicylic acid induce multiple stress tolerance in bean and tomato plants. - Plant Growth Regul. 30: 157-161, 2000.

Sheokand S., Kumari A., Sawhney V.: Effect of nitric oxide and putrescine on antioxidative responses under $\mathrm{NaCl}$ stress in chickpea plants. - Physiol. Mol. Biol. Plant. 14: 355-362, 2008.

Silveira V., De Vita A.M., Macedo A.F. et al.: Morphological and polyamine content changes in embryogenic and nonembryogenic callus of sugarcane. - Plant Cell Tiss. Org. 114: 351-364, 2013.

Singh B., Usha K.: Salicylic acid induced physiological and biochemical changes in wheat seedlings under water stress. Plant Growth Regul. 39: 137-141, 2003.

Slaymaker D.H., Navarre D.A., Clark D. et al.: The tobacco salicylic acid-binding protein 3 (SABP3) is the chloroplast carbonic anhydrase, which exhibits antioxidant activity and plays a role in the hypersensitive defense response. - P. Natl. Acad. Sci. USA 99: 11640-11645, 2002.

Soussi M., Ocaña A., Lluch C.: Effect of salt stress growth, photosynthesis and nitrogen fixation in chick- (Cicer arietinum L.). - J. Exp. Bot. 49: 1329-1337, 1998.

Strobel N.E., Kuc A.: Chemical and biological inducers of systemic acquired resistance to pathogens protect cucumber and tobacco from damage caused by paraquat and cupric chloride. - Phytopathology 85: 1306-1310, 1995.

Sudhir P., Murthy S.D.S.: Effects of salt stress on basic processes of photosynthesis. - Photosynthetica 42: 481-486, 2004.

Sullivan C.Y., Ross W.M.: Selecting the drought and heat resistance in grain sorghum. - In: Mussel H, Staples R.C. (ed.): Stress Physiology in Crop Plants. Pp. 263-281. John Wiley \& Sons, Inc, New York 1979.
Sung M.S., Chow T.J., Lee T.M.: Polyamine acclimation alleviates hypersalinity-induced oxidative stress in a marine green macroalga, Ulva fasciata, by modulation of antioxidative enzyme gene. - J. Phycol. 47: 538-547, 2011.

Szabados L., Savouré A.: Proline: a multifunctional amino acid. - Trends Plant Sci. 15: 89-97, 2010.

Szepesi A., Csiszár J., Bajkán S.Z. et al.: Role of salicylic acid pre-treatment on the acclimation of tomato plants to salt- and osmotic stress. - Acta Biol. Szeged 49: 123-125, 2005.

Tabor C.W., Tabor H.: Polyamines. - Annu. Rev. Biochem. 5: 749-790, 1984.

Tadayon M.R., Emam Y.: Physiological and morphological responses of two barley cultivars to salt stress and their correlation with grain yield. - Agric. Nat. Res. Sci. Tech. 11: 253-262, 2007.

Tanou G., Filippou P., Belghazi M. et al.: Oxidative and nitrosative-based signaling and associated post-translational modifications orchestrate the acclimation of citrus plants to salinity stress. - Plant J. 72: 585-599, 2012.

Tanou G., Ziogas V., Belghazi M. et al.: Polyamines reprogram oxidative and nitrosative status and the proteome of citrus plants exposed to salinity stress. - Plant Cell Environ. 37: 864885, 2014.

Tari I., Csiszár J., Szalai G. et al.: Acclimation of tomato plants to salinity stress after a salicylic acid pre-treatment. - Acta Biol. Szeged 46: 55-56, 2002.

Tiburcio A.F., Kaur-Sawhney R., Galston A.W.: Polyamine metabolism. - In: Miflin B.J., Lea P.J. (ed.): Intermedatory Nitrogen Metabolism. The Biochem of Plants. Pp. 283-325. Academic Press, Cambridge1990.

Tisi A., Federico R., Moreno S. et al.: Perturbation of polyamine catabolism can strongly affect root development and xylem differentiation. - Plant Physiol. 157: 200-215, 2011.

Unni S., Rao K.K.: Protein and lipopolysaccharide profiles of a salt-sensitive Rhizobium sp. and its exopolysaccharidedeficient mutant. - Soil Biol. Biochem. 33: 111-115, 2001.

Uzunova A.N., Popova L.P.: Effect of salicylic acid on leaf anatomy and chloroplast ultrastructure of barley plants. Photosynthetica 38: 243-250, 2000.

Verslues P.E., Agarwal M., Katiyar-Agarwal S. et al.: Methods and concepts in quantifying resistance to drought, salt and freezing, abiotic stresses that affect plant water status. - Plant J. 45: 523-539, 2006.

Wang M., Jiang W., Yu H.: Effects of exogenous epibrassinolide on photosynthetic characteristics in tomato (Lycopersicon esculentum Mill) seedlings under weak light stress. - J Agr. Food Chem. 8: 3642-3645, 2010.

Wani A.S., Ahmad A., Hayat S. et al.: Is foliar spray of proline sufficient for mitigation of salt stress in Brassica juncea cultivars? - Environ. Sci. Pollut. R. 23: 13413-13423, 2016.

Wani A.S., Ahmad A., Hayat S. et al.: Salt-induced modulation in growth, photosynthesis and antioxidant system in two varieties of Brassica juncea. - Saudi J. Biol. Sci. 20: 183-193, 2013.

Wu X.X., Ding H.D., Zhu Z.W. et al.: Effects of 24-epibrassinolide on photosynthesis of eggplant (Solanum melongena L.) seedlings under salt stress. - Afr. J. Biotechnol. 11: 86658671,2012

Xu G., Magen H., Tarchitzky J. et al.: Advances in chloride nutrition of plants. - Adv. Agr. 68: 97-150, 1999.

Yamaguchi K., Takahashi Y., Berberich T. et al.: A protective role for the polyamine spermine against drought stress in Arabidopsis. - Biochem. Biophys. Res. Co. 352: 486-490, 2007. 
Yang W.J., Rich P.J., Axtell J.D. et al.: Genotypic variation for glycine betaine in Sorghum. - Crop Sci. 43: 162-169, 2003.

Yusuf M., Hasan S.A., Ali B. et al.: Effect of salicylic acid on salinity induced changes in Brassica juncea. - J. Integr. Plant. Biol. 50: 1-4, 2008.
Zheng C., Jiang D., Liu F. et al.: Effects of salt and water logging stresses and their combination on leaf photosynthesis, chloroplast ATP synthesis, and antioxidant capacity in wheat. - Plant Sci. 176: 575-582, 2009. 